Article

\title{
Sustainable Tourism Planning: A Strategy for Oecusse-Ambeno, East Timor
}

\author{
Miguel Amado * and Evelina Rodrigues
}

check for updates

Citation: Amado, M.; Rodrigues, E. Sustainable Tourism Planning: A Strategy for Oecusse-Ambeno, East Timor. Urban Sci. 2021, 5, 73. https:// doi.org/10.3390/urbansci5040073

Academic Editors: Atiq Zaman and Mohammad Swapan

Received: 6 September 2021

Accepted: 22 September 2021

Published: 28 September 2021

Publisher's Note: MDPI stays neutral with regard to jurisdictional claims in published maps and institutional affiliations.

Copyright: (c) 2021 by the authors. Licensee MDPI, Basel, Switzerland. This article is an open access article distributed under the terms and conditions of the Creative Commons Attribution (CC BY) license (https:/ / creativecommons.org/licenses/by/ $4.0 /$ )
CERIS-Civil Engineering Research and Innovation for Sustainability Instituto, Superior Técnico of Universidade de Lisboa, 1049-001 Lisboa, Portugal; ebm@fct.unl.pt

* Correspondence: miguel.amado@edu.ulisboa.pt

\begin{abstract}
This paper aims to explore the topic of sustainable tourism activity. The subject has emerged in the last two decades from discussions about the content of the report, Our Common Future. The decision to transform developing countries into new offerings for ecological and cultural tourism brings to the discussion the imprecise and conflicting definitions of the concept and the need to distinguish between the development of tourism, and sustainable tourism supported on the principles of sustainable development. The research reviews the environmental and social contexts of the Oecusse-Ambeno region in East Timor. It discusses the new sustainable tourism activities in the region with the need to ensure that the concept includes a strong base of perceived authenticity in the human context and the physical environment. The problems of the carrying capacity control of tourism development, and the term's relevance to mass or conventional tourism, are strategically anticipated. The region is confronted with an offer that supports more peacefulness, and that is more aligned to the culture and the natural environment. This paper provides insight into the ways in which tourists perceive the authenticity of visitor attractions and highlights the importance of the cultural and environmental values of tourism destinations for strategic planning and marketing purposes.
\end{abstract}

Keywords: tourism; sustainable; planning

\section{Introduction \\ 1.1. East Timor}

A foreign country occupied Timor-Leste for over two decades and left devastating social, economic, and environmental impacts. This situation has not been much investigated, given the problems of international policy, making this investigation opportune. However, the country's development problems are a real issue, and it is crucial to understand and identify which strategies should be followed in order to promote the region's sustainable development, as is the case with tourism. Disasters that have occurred have profound impacts on individuals, organizations, communities, and the conditions for tourism activities [1]. The repercussions of a war disaster directly affect the tourism sector of the destination country, but indirect consequences for travel to and from the affected region are also conceivable, as in the case of the Oecusse enclave in East Timor.

Vulnerable populations are displaced, secondary squatters complicate titles, and political actors capitalize on the breakdown of governance to consolidate control of the land. Land-related challenges are rarely addressed holistically because the land is a crosscutting issue that involves isolated domains of peacekeeping, humanitarian aid, and development assistance.

The importance and need for a contextualized approach to post-conflict land policy planning play an essential role. It can operate as an alternative to rights-based models of property restitution to the dispossessed and can create conditions for future entrepreneurship in the tourism sector [2]. 
Considering the actual situation of the Oecusse-Ambeno enclave in Timor-Leste, the research developed addresses the potential of sustainable tourism activity to guarantee a development process supported by the authenticity of the human physical environment.

\subsection{Sustainable Tourism Planning}

Since discussions about the content of the "Our Common Future" report, the World Tourism Organization (WTO) started suggesting that tourism can be an opportunity to emerge from the crisis. The resolution to transform developing countries into new offerings for ecological and cultural tourism brings to the discussion the imprecise and conflicting definitions of the concepts, and the need to distinguish between tourism development, and sustainable tourism based on sustainable development principles [3].

The problems of the system's carrying capacity, the control of tourism development, and the relevance of mass tourism or conventional tourism have been anticipated strategically. The new tourism activities in place as sustainable tourism transform the vulnerability of the place and change market perceptions that need the concept to include a strong base of perceived authenticity in the local human context and the physical environment. It is confronted with an offer supported by more peacefulness, cultural recognition, and alignment with the natural environment. This text provides insight into the ways tourists perceive the authenticity of visited attractions and highlights the importance of the cultural and environmental values of tourism destinations for strategic planning and marketing purposes.

\section{"(...)Tourism has become a key industry for the region and one of the most important} value-added and employment" [4].

In many vulnerable countries, tourism has witnessed a growth in its importance in socioeconomic matters. It has become one of the most significant export sectors and a recognized tool for achieving sustainable development in developing countries [5,6].

The contribution of the tourism sector's growth is seen in the increase of the local population's income. This reality is achieved by creating employment opportunities. The national average annual growth rate of international tourism arrivals in developing countries from 1990-2005 was 6.5\%, compared with $4.1 \%$ of world growth in the same period [7].

The tourism sector also contributes to economic development in at least two additional ways on the international level. Firstly, it increases efficiency through competition between firms and other international tourist destinations [8] and, secondly, it promotes local companies at the national economic scale [9].

Tourism is also an essential foreign exchange and investment source and generates employment and business opportunities [10]. Furthermore, the tourism sector is responsible for one in ten jobs in the world's population. Tourism activity creates connections with many other economic sectors and is a valuable contributor to development strategies. Nevertheless, tourism activities may be detrimental to the natural environment and the community's social and cultural characteristics [11,12]. Stronza and Gordillo (2008) argue that tourism has been discussed for its potential to cause negative impacts on natural habitats and local communities. Moreover, the tourism industry tends to generate negative environmental and sociocultural disturbances [12], such as water and air pollution, the destruction of cultural values, and the affirmation of foreign cultures.

The critical relationship between tourism and natural heritage is a central theme when considering policies and actions aimed at preserving the local identity and managing activity in more sensitive areas. Particular attention should be paid to the mitigation and adaptation of the tourism sector to climate change effects and now, with the world's countries under confinement, the effects of the COVID-19 pandemic [13]. The use of mechanisms to assess the sustainability of tourism activity is vital for monitoring the impacts regarding the relationship between tourism activity and the preservation and management of natural and cultural heritages, as well as many other aspects, such as resource use, efficiency concerning climate change, enhancing the sustainability of tourism 
development and operation, and, lastly, the measuring and monitoring of tourism impacts within the context of sustainable development principles.

When applying sustainable development principles to the tourism sector, it is possible to adopt different approaches. However, the outcome always results in an approach to the development model that seeks a balance between different and competing needs in the face of the limitations that society faces in environmental, social, and economic development matters. Tourism development, based on an economic impulsiveness, does not always consider its activity's immediate and long-term impacts. The results have consequences that require more careful and preventive treatment by those responsible for the decisions. The damage that this type of approach can result in are not always local and can include large-scale financial crises caused by irresponsible banks, or changes in the global climate resulting from the dependence on fossil fuels. Therefore, the more unsustainable the development strategy is, the more frequent and severe the consequences will be. Hence the urgency of preparing a response action from the start that keeps the long-term effects in mind.

The use of sustainable development principles has increased in the last decades and, nowadays, it receives attention for the processes involving interventions in the territory that constitutes the base for human activities. The sustainability concept was introduced in two of the United Nations conferences on environment and development [14], where the need for new global and local development strategies was recognized [15]. Sustainable development requires us to "meet the needs of the present, without compromising the ability of the future generations to meet their own needs" [16] by guaranteeing environmental quality, economic development, and social equity through an intergenerational perspective. Therefore, sustainability can be an archiving practice throughout planning tourism interventions and can guarantee an integrated approach to environmental, economic, social, and cultural factors. The planning process has a fundamental role in supporting human activities, being the basis for land-use changes. A vital part of territory management can satisfy the population's environmental, economic, and social needs and promote conformity between the main stakeholders. As mentioned in the Green Book for the Urban Environment [17], the city should be the driving force towards the actions leading to sustainable development.

The efficient implementation in the tourism sector of sustainable development principles will only be possible through territorial planning. After all, "... the regional and urban planning is directed to the communities, population and to the use of land and economics' facilities, through processes of goals definition, planning actions and rules..." [18]. The urban planning process has a fundamental role in carrying out sustainability principles and goals [15].

In the post-independence period, the tourism sector in Timor-Leste saw the possibility of opening up to the outside world and integrating the supply area to international tourism, having started its participation in the events of the World Tourism Organization (WTO) and the Pacific Asia Travel Association (PATA).

The Ministry of Development and Environment coordinated tourism areas in the Secretary of State for Tourism, Environment and Investment from 2002 to 2005. The country's political power determined the will of the State: the country would become an example of sustainable development in tourism.

In order to develop and apply responsible tourism to the current ecotourism development conditions in Oecusse-Ambeno, we need to consider the context of a balance between the tourism sector and the complex socioeconomic interests of tourism stakeholders, government policies, and the preservation of the ecosystem [19].

Responsible tourism has a principle of social sustainability. Undoubtedly, development needs to be compatible with local communities' traditional values while promoting their identity and the associated cultural values and, thus, guaranteeing their future continuity.

However, the concept of sustainable tourism development involves more dimensions within the framework of the relationship between economic, social, and cultural develop- 
ment and its suitability to the environment, making use of this without compromising its characteristics, maintenance, or regeneration capacity [20].

The practice of sustainable urban planning is the path for determining the actions to be taken to ensure the efficiency of tourism interventions with regard to its timing and territorial actions (local, regional, global). The definition of actions is one of the fundamental capabilities of the planning process that falls within sustainable development.

Planning for sustainable tourism development requires environmental protection and preservation planning and, therefore, addresses a wide range of research and analysis activities before arriving at the decision-making process that foresees development. All activities carried out minimized the pressure on resource use without prior evaluation [21].

The discussions about the introduction of sustainability principles in the tourism sector lead to a development process guided by the same values [22].

Tourism activity aims to create benefits for communities in developing countries and, with a committed government, ensures sustainable tourism development. The results may increase the quality of life in various ways, such as better infrastructure and facilities, as well as opportunities for jobs [23]. This strategy would bring economic enhancement, particularly to the enclave areas that struggle to assert themselves as more attractive places in natural and cultural terms.

The promotion of tourism in enclave territories takes place mainly in developing countries. The understanding of the enclave concept has been based on processes, such as resort tourism, cruise tourism, theme parks, and cases in which the contribution to local communities is reduced. The reality is not the same because, in the case of territorial enclaves, it is the entire population of the enclave and the country itself that benefits $[24,25]$.

Based on the guidelines of the Strategic Development Plan 2011-2030-Government of the Democratic Republic of East Timor, 2011 [26], the setup of the Oecusse-Ambeno region, when completed, may be able to determine its path within a sustainable development framework.

Like most developing countries, the region has a low infrastructure level, a high level of poverty, and insufficient economic resources to reverse the path.

It is common in vulnerable countries to see that the existing isolation induces cultural, social, economic, and behavioral characteristics, with consequences that do not appear ideal for developing tourism policy.

Sustainable development in the tourism sector aims to articulate reconciling conflicting value positions concerning the environment [27] and the socioeconomic. The growing contribution of tourism to adaptation to climate change has demonstrated how it can guarantee greater longevity for communities in enclave areas that are already fragile and where it is a significant political problem [28]. Individualized and isolated initiatives are conducive to the sustainable tourism development model, replicating the characteristics of other destinations especially those with protected and vulnerable areas whose development processes are highly dependent on access planning, minimal infrastructure, regulation and monitoring, thus helping to conserve natural resources [29,30].

The Oecusse-Ambeno region presents the following characteristics and challenges: a low level of education, low quality of public health services, scarcity of health equipment, and minimal public investment to encourage a solid sustainable development process.

Rural areas have less access to investment opportunities for development based on policies or programs designed to stimulate them, leaving them vulnerable and prone to less sustainable interventions. When considering rural development, the public sector usually focuses on promoting an increase in the productivity of the agricultural sector, leaving the tourism sector dependent on private investment. However, this positioning does not guarantee a reversal of the population's lack of resources and capabilities in order to improve their quality of life and raise the income of rural families.

However, the prospect of growth, and the need to attract investment in tourism, ultimately influence decision-making. In countries with a centralized decision-making 
model, the risk of accepting less sustainable development proposals is more significant, as there is less involvement of the local administrative structures [31].

On the other hand, the context of the region as an enclave makes it essential that Indonesia becomes a potential market in order to ensure demand and an efficient relationship between infrastructure investments and the installation of equipment and tourism units.

Adaptation to the reality of the place, the population, and the territory's natural potential is rarely considered, resulting in exploitation without a qualifying return for the affected population [28,32]. At the same time, the fragile situation of the population in the enclave, due to the lack of skills, makes it easier to implement more sustainable development models adapted to a technological level more adapted to ecological solutions [33].

Tourism development in a fragile region implies minor unanticipated impacts that can cause environmental and social damage [34]. In practice, the most fragile environments are areas with the highest tourism potential, so the activity should support nature conservation, avoiding the most harmful land uses. Impacts, such as the definition of poles and trampling trails, are easier to quantify and can be minimized by the economic activity of local guides, which benefits the economy. Other significant activities, such as constructing housing units, should be evaluated based on the existence of a public land bank allocated to the nature tourism industry so that nature recreation can be restricted to minimal impact activities and nature tourism can continue to grow in less fragile environments. [35].

The planning framework for the region of Oecusse-Ambeno must ensure a set of sustainability strategies specifically adapted to the region in its territorial planning process, with the development of various areas of opportunity, such as tourism. This action will result in more robust socioeconomic growth, which is why the investigation added the tourism aspect to the territorial planning model. The region will strengthen its natural heritage and strengthen its cultural identity.

\section{Materials and Methods}

The applied methodology is based on field research and personal interviews developed from the master plan for the Oecusse-Ambeno region. The thematic for tourism research considers the political, technical, and administrative staff, volunteers from the local population, and a few tourists present in the region [36].

When developing a set of strategies for a thematic area, the research's focus also integrates the social and cultural contexts when working in highly politicized environments [37]. Therefore, the methodology must aggregate activities that involve talking with the population and public entities, and tasks that result in the analysis of more spontaneous behaviors and field survey work that aids the understanding and evaluation of the real potential of the area to be intervened upon.

Nonintrusive research methods are supported by what can be seen around us, and can be considered sources of information and data.

In the investigation, and because of the association with the strategy-oriented planning model, the principles of project management and practical problem-solving, and issues related to the time, cost, and data of the allocation of human and material resources, are listed.

These issues influenced the choice of the methodology used that, in this case, are mainly qualitative and quantitative by also utilizing an overview on different scales to be applied to the tourist destination of Oecusse-Ambeno [38].

Two general lines of necessary information inform the research. The first is of quantitative orientation and refers to specific data on spatial characteristics and geographical parameters, demographic and economic forecasts, and the touristic area. The second, and more complex, is the attempt to understand communities' social and cultural realities and use this information to design the planning decision process, which will support future strategies for the sectoral areas [39].

This process also reinforces various communication strategies to be thought about with official authorities and in consultation with local communities [40]. 
In the research projects, the qualitative approaches were integrated to generate the necessary data to formulate and inform the implementation of the spatial planning policy in articulation with the construction of the tourism sector's strategies. The research structures and results appear robust enough to provide the tourism planning team with useful information and data validity [41].

The methodology applied in the present research adopted a four-phase structure:

First phase-bibliographical review and characterization studies of the territory.

Second phase - comparative diagnostics based on examples of good practice and SWOT analysis. Third phase-presentation of a proposal of a tourism development network in the region, zoning areas of opportunity for different and specific opportunities.

Fourth phase-definition of strategies and guidelines to support intervention programs per identified subareas (according to the zoning presented on phase three) within the intervention area [15].

\section{Results}

The results achieved from the research methodology conducted are presented through subtitles, where the path and interpretations that enable the conclusions reached are concisely described.

\subsection{Oecusse-Ambeno Region}

The Oecusse-Ambeno region (total area of $815 \mathrm{~km}^{2}$ ) in East Timor (Figure 1) has essential ecological habitats, such as dense forests and coral reefs, as well as social and economic ones. The soil and the flooded areas where agriculture and rice fields are a means of food support present potential environmental risks, such as landslides from unstable slopes, and other related extreme events.

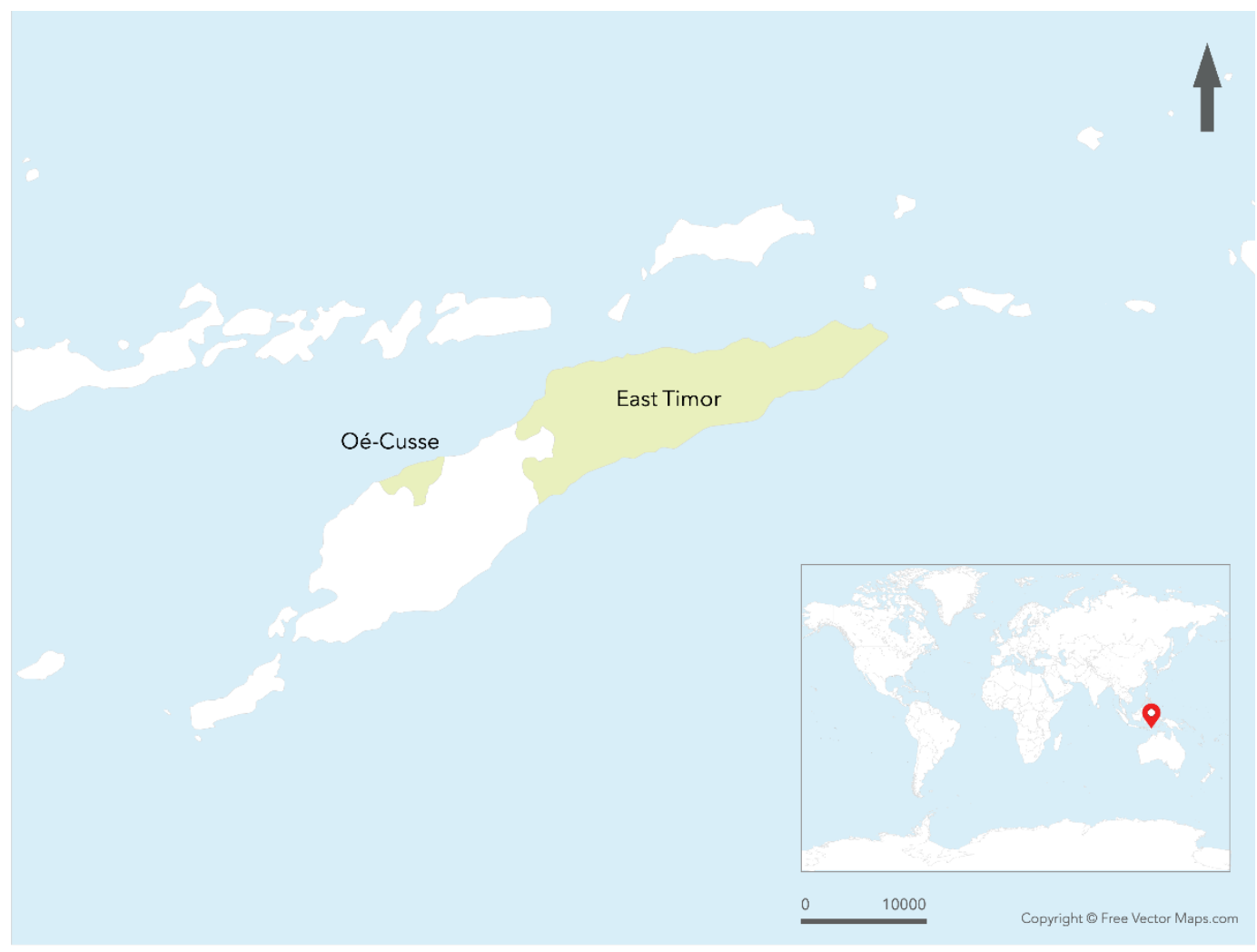

Figure 1. Oecusse-Ambeno region in East Timor map (Source: Free Vector Maps.com, 2013, accessed on 22 April 2021).

This region is dominated by the Ribeira do Tono basin. The region is generally very bumpy with an irregular relief, attenuating in the coast, and more mountainous 
in the interior. About $46 \%$ of the territory presents very steep slopes. It has a complex hydrographic network due to the presence of sharp slopes.

The precipitation distribution throughout the year is irregular, occurring mainly from November to March. Maximum daily rainfall is relatively high in the region (up to $400 \mathrm{~mm}$ ), particularly in January and February.

The territory presents excellent and often still soil cover that becomes unstable by the effects of rainy torrents during the season of high annual precipitation. It is well known that the most productive areas correspond to the Tono River's floodplain, where rice is grown.

The environment and its ecosystems are sensitive areas that need to be safeguarded and protected for the future. It is fundamental to ensure the protection of natural capital that supports local human life, and to secure a set of ecosystem services that will be safe in the future.

The Oecusse-Ambeno region's landscape has been shaped by human activities, which have visibly impacted the vegetation, reflecting the practices of agriculture that occur. Furthermore, fire and the demand for wood as fuel have cut species of trees with high commercial value over the last years. The territory is now facing extensive deforestation and, consequently, there is increased soil erosion, reduced biodiversity, and a loss in the commercial potential of the mined species.

The area of Cutete is particularly relevant for its dense forest at a high altitude and is in good condition because of the steep slopes. The Monte Manoleu area includes a forest zone at a high altitude, dense coastal forest, and also includes the mangrove zone of Citrana. These areas are protected by the traditional practices, "Tara Bandu", which are well-preserved, and efforts should be made to ensure the continuity of their preservation and protection.

In mountainous areas, the territory is dominated by savanna areas, with a low degree of vegetation cover and sparse arboreal elements dominated by Eucalyptus alba, Acacia sp., Allocasuarina, Casuarinas, and Tamarindus.

The coastal forest is a narrow space with little diversity of vegetal species, presenting grasses with scattered arboreal elements, such as Tamarindus indica, Corypha utan, Borassus flabellifer, Schleichera oleosa, Ziziphus mauritiana, Acacia sp., among others. Regulation 2000/19 UNTAET protects the mangrove species, which are also protected by traditional practices (Tara Bandu).

Several sensitive habitats need to be preserved in marine areas, such as coral reefs and marine prairies, where species, such as Dugong dugon, occur. The importance of their protection is in the richness they provide to the habitat and the fact that they have a vulnerability status alert based on the IUCN Red List, making protection essential.

The Indonesian occupation period caused a disaster-like context corresponding to a serious interruption of the community's operation, involving widespread human, material, economic, and environmental losses and impacts that conditioned the beginning of strategy development for the tourism sector [42].

In the period between 1975 and 1999, the Indonesian occupation promoted an unknown number of deaths in East Timor due to violence and famine [43]. According to the National Directorate of Statistics of Timor-Leste [44], the estimated number of victims in the first years of undue occupation was between 60,000 and 300,000.

The war and occupation of the territory caused an indirect mortality in the population that was much higher than the number of deaths on the battlefield $[45,46]$. The immediate impact of the war situation interrupted medical systems, and in-migration flows increased poor living and sanitary conditions and scarcer access to available food.

East Timor is a small country but is also a critical case study of the excess mortality seen during the period of occupation by Indonesia [47]. The estimated number of casualties in the first years of occupation indicates that the Indonesian invasion of Timor-Leste produced one of the highest proportionate death tolls of any war or mass murder in twentieth-century history [48]. 
More recent studies by the Commission for Reception, Truth and Reconciliation in Timor-Leste made it possible to fix the number of direct victims of the Indonesian occupation over 24 years at a value greater than 102,800 [49]. This number required adding the effects of the war situation, one of which was a reversal in the number of births in East Timor. These disasters constituted abrupt changes that shocked the system in which tourism is embedded [50] and generated a profound impact on individuals, organizations and communities, and tourism activities [1].

The integration of tourism activity as a strategy to reply to existing social, economic, and environmental disaster management models can be used as an integrated action, where the population and environment simultaneously take part in the new opportunity scenario [51,52].

The impact on population growth, economic change, and the restructuring of the territory's administration has led to an increased urbanization that attracts more people and leads to greater infrastructural and environmental changes.

An important challenge facing the tourism sector in East Timor is anticipating the threat of crises precipitated by natural and people-made catastrophes, and adequately preparing for them.

Despite increased research on this issue, there is still a considerable lack of clarity on the impacts of crises on the tourism industry [53].

With the support of a comprehensive discussion, analysis, and synthesis of the literature on crisis management, the local administration became more proactive in preparing and dealing with past crises and anticipating the impact on the tourism sector [54].

This program aims to create a sustainable tourism destination-a network of activities based on nature, people, and culture, that contributes to the experiences of rest and happiness, and that seeks a balance between the environment, the economy, and social interactions. The sustainability of this tourist destination is at the heart of a strategy that also values the environment.

The integrated touristic resources cover a mix and include the coastal sea and diving, hiking in nature, on social routes and in landscapes, and experiencing local communities (Figure 2) [26].

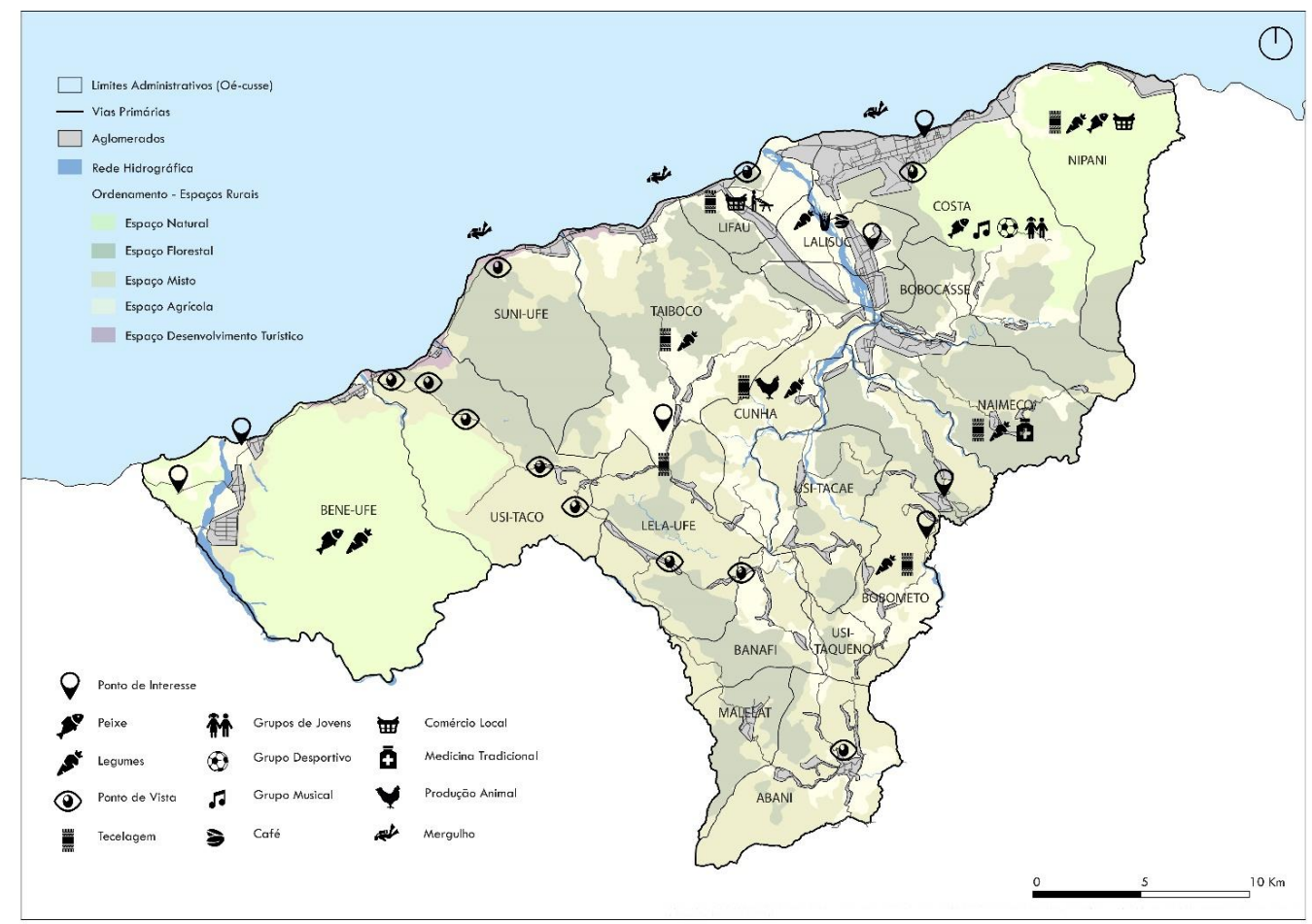

Figure 2. Potential touristic resources (Source: GEOTPU.LAB, 2016). 
The region already has several hotel units, almost all of them located in Pante Macassar city and near the seafront. The demand for this touristic offering is low and mostly linked to the business sector. Cultural tourism is almost nonexistent because of the low frequency of flights and the bureaucracy involved when traveling through Indonesia.

The proposal of developing a Hotel in Pante Macassar with a capacity of 250 beds creates the opportunity to have new jobs and new offers for the tourism sector. It is believed that the location of this hotel will alter the panorama of the tourist offerings for several years to come, as it is positioned next to an area of ponds and a rice paddy in the capital city of the region and it provides a facility to hold corporate, business, and scientific meetings.

The region has also planned heritage interventions with the recovery of the Monument of Lifau, a building inherited from the time of the Portuguese colonial occupation, meant to operate as a tourist information office and cultural hub. The proposal is based on a project developed by the Local Technical Office-GTA-ZEESM, in association with GEOTPULAB-IST UL, which, combined with the oceanfront's requalification of the city of Pante Macassar, incorporate excellent conditions for beach use.

The offering of tourist accommodations is complemented further with other small units that offer beds for visitors flying into the region. Nevertheless, the low demand for tourist attractions in the region, and the sector's lack of regulation, accounted for the lack of installed capacity in the region.

Apart from the natural and cultural resources, which have not been adequately explored, human resources and the poor quality of living of the local population stand out. The population culture reveals 20 years of the embedded memories of military occupation, making it impossible to develop skills. This recent historical background has resulted in the characterization of the region's population as fragile, with traumatic memories, and very dependent on aid at all levels.

The region of Oecusse-Ambeno now seeks to promote itself and better services and infrastructures supporting tourism activity, including energy, water, and sanitation infrastructure networks with a higher level of service and quality. Moreover, it intends to make the public sector the supplier and support to generate the necessary conditions to permanently attract tourists from all over the world (Figure 3).



Figure 3. Tourism priority areas (Source: GEOTPU.LAB, 2016). 


\subsection{Strategy}

The strategy for developing tourism activity in Oecusse-Ambeno is based on two fundamental concepts: sustainable tourism and community tourism. Sustainable tourism (ecotourism) links to the management and maintenance of resources, and environmental, social, and economic conditions, avoiding their overexploitation so that future generations can enjoy them [55].

The marketability of individual destinations and global tourism is vulnerable to sudden changes in market perceptions. Acts of man or nature can transform the reputation, desirability, and marketability of the most popular tourism destinations overnight [56].

A sustainable community-wide tourism paradigm can be achieved if the tourism activities guarantee equity in distributing the benefits obtained and seek to maintain the integrity and traditions of the people as a fundamental resource [57].

In this framework, and according to existing local resources, there are four distinct vectors of potential exploitation that the tourism sector in this region could explore:

Coastal tourism-bathing associated with diving and other activities linked to the sea, such as nautical recreation or fishing.

Nature tourism-linked to the exploration and use of the natural areas of the territory, routes and rails, and relevant fauna, flora, and landscape areas.

Cultural tourism - where the population clusters of the territory offer cultural experiences of the traditions and ways of life of the inhabitants, and where craftsmanship, the techniques used in their creation, and the religious and architectural heritages are resources to explore for the benefit of all.

Business tourism-focuses on Pante Macassar and is directed to holding events, meetings, conferences, and support for the business activities throughout the region [33] (Figure 4).

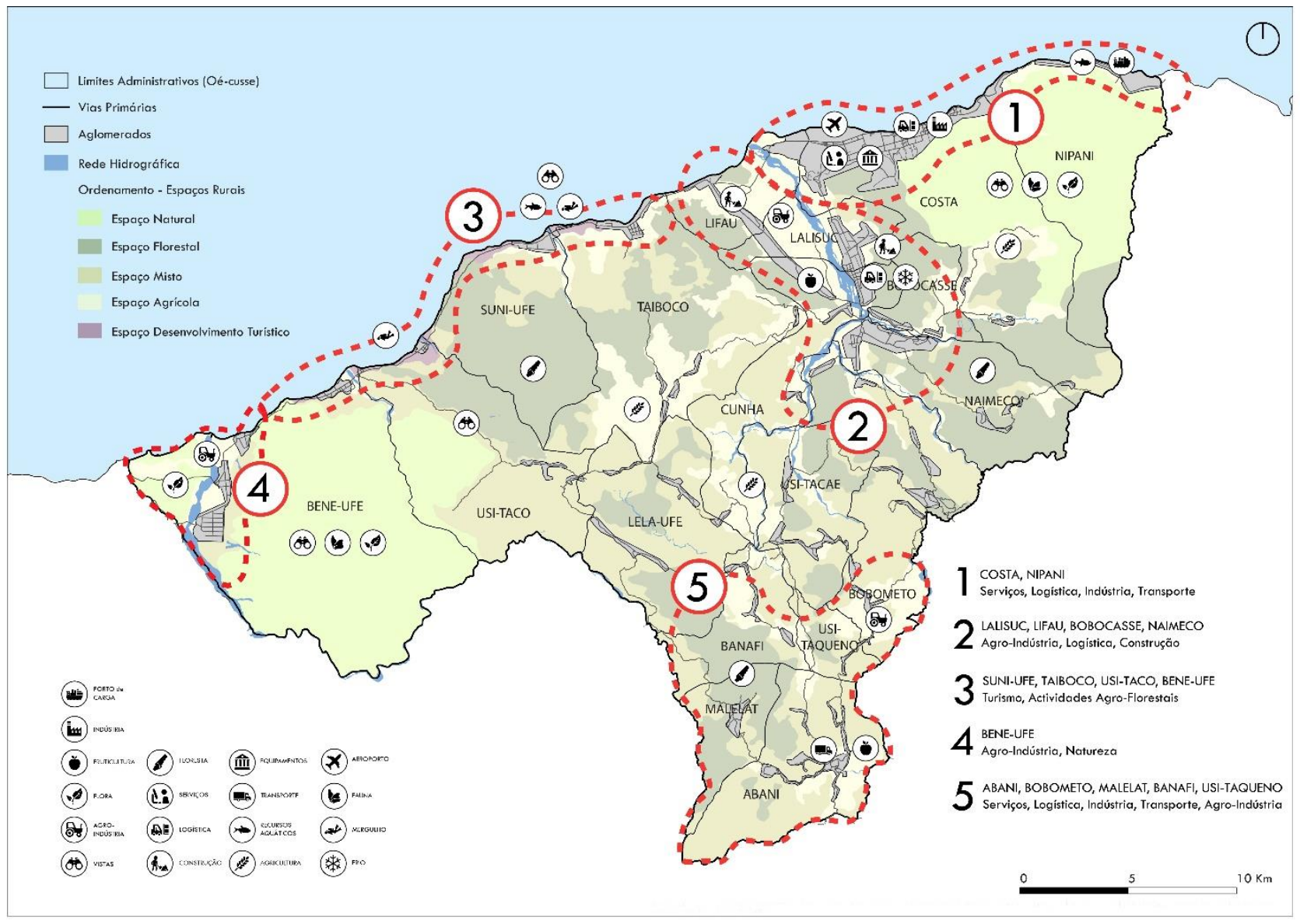

Figure 4. Strategy potential map (GEOTPU.LAB, 2016). 
Among the existing resources that can support the tourist development strategy of Oecusse-Ambeno, the diversity of the territory stands out for its richness and potential for the tourism sector, namely, the region's natural characteristics and the sociocultural experiences it provides, such as: traditional, authentic living communities and unique products and modes of production; a diverse landscape with remarkable elements due to its morphology and dimensions; old forests in which religious significance is a unique component in the geographical area; the diversity of native fauna and flora; a subaquatic environment rich in coral reefs and protected fauna species, such as the Dugong.

Another enjoyable visit is to the beaches and mangroves where there are water crocodiles (C. porosus), which are also considered sacred in East Timor.

East Timor has an extensive barrier of coral reefs and is ranked among the world's best places for underwater activities.

This type of tourism presents enormous potential for the region, but the offering of services to support this potential is almost nonexistent.

The coral barrier serves as a shelter for many sea creatures, from turtles to whales, to the most diverse species of colorful tropical fish and clownfish.

Another area with high potential in Oecusse-Ambeno is the activity of trekking. Since the first walks in the region, connections have been made with the chiefs, leaders, and guides of the Sucos (villages), who share knowledge of the local geography and culture, ensuring the safety and development of walking routes. The trekking activities are already a substantial opportunity in the region's tourism offerings because of the reduced environmental impact and the promotion of natural wealth, providing real environmental and cultural opportunities, based on the concept of sustainable environmental tourism.

Within a few hours of walking in the forests and along steep paths, it is possible to reach mountain peaks, passing different villages that provide the opportunity to experience the local communities and their traditions and customs.

\subsection{Proposal}

"In nature, nothing is taken away except pictures. Nothing is left but footprints. Nothing leads to anything but memories." (In Arrábida Unknown, Gaspar (2012)).

The strategy design for the Tourism Development of Oecusse-Ambeno (Figure 5) provides the opportunity for the creation of a tourist destination supported on sustainable development principles with the cultural and community guidelines as follows: (i) Increase the competitiveness of the region while making South Asia a sustainable tourism destination; (ii) Ensure fairness in the distribution of benefits and inter-and intra-generational solidarity; (iii) Develop proposals that promote the cultural and community components valuable for tourism and make them available to informed decision-makers, politicians, and stakeholders; (iv) Ensure that natural resources are preserved at a high level and that quality, as an essential value, is present in all the actions taken for the development of the region; (v) Ensure the formation of solid human and social capital $[57,58]$. 


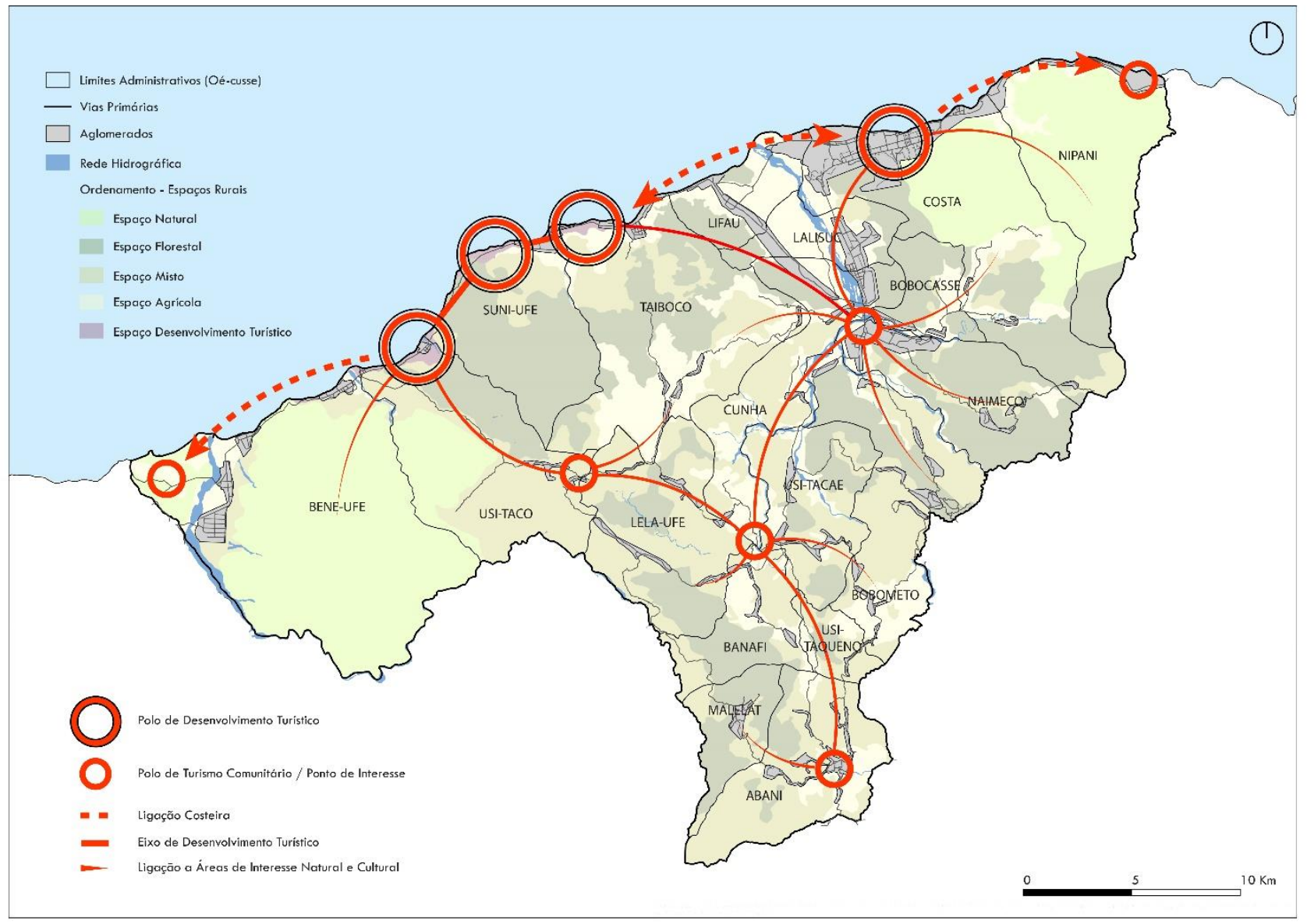

Figure 5. Touristic development points (GEOTPU.LAB, 2016).

Several factors are considered necessary in order to implement the strategy and planned actions for Oecusse-Ambeno. These factors are related to the operation of culture and institutions in vulnerable countries whose resolution is complex. The necessary adaptation and transition to the population integration in the task lists several points to be implemented and are listed below:

- Promotion of cohesion and community organization by including all groups and age groups of the population in the participatory process.

- Priority preservation of the territory and natural resources are the basis for defining the conceptual and institutional basis of the intervention.

- Transparency and precaution in transferring the risks, benefits, and costs.

- Encouraging the maintenance of traditions and natural and cultural heritage.

- Relevance to actions to remove cultural barriers and institutions in developing countries.

- Context supply for the intensive use of the local population in economic activities linked to tourism.

- Marketing of the destination.

- Planning and monitoring visitor flows and its impact on resources-LAC (limit of acceptable change).

- Partnerships with private institutions and nongovernmental organizations that can bring know-how and investment.

- Contextualized approaches to the socioeconomic reality.

- Good access, infrastructure levels, and public services.

The guidelines listed need to be put in place through several actions that have been devised related to sustainable tourism in order to create the basis for this activity's success 
in Oecusse-Ambeno. The authority of the region must run these actions past the Tourism Secretary in connection with the GTA-ZEESM.

- Regulation and policies that promote tourism as an activity at the level of the issuance of visas and better access through air flights, as a precaution in the new tourism developments.

- Promotion of quality destinations and products, based on the integration of local communities, their identity and way of life, to maximize the economic gains for the region while avoiding the leakage of capital outward.

- Creation of a team responsible for marketing targeting a global audience, working with tour operators and local communities, studying consumers and looking for diversification of supply and advantageous public-private partnerships.

- Build a network of activities in the various cultural and ecological components, positioning the destination as an example of sustainability in the region.

- Training and capacity-building programs in tourism in the national educational curriculum, vocational and technical education, as well as at the level of training community facilitators to support tourism in each culture.

- Provide continuous training to workers in the sector, and maintaining the competitiveness of the destination through their capacity for innovation.

- Promote a safe and comfortable environment to minimize intracommunity conflicts and crime and develop a response plan and natural disasters management.

- Establish partnerships between the state and other actors in the territory to develop infrastructures (transport, water, energy) through mechanisms for capturing and managing the investment.

- Ensure and seek funding sources with lasting budgets that alleviate local budgets and regional authorities.

- Approve a territorial model guaranteeing the preservation of natural and cultural resources essential for tourism promotion.

- Integrate good practices in environmental conservation into tourist activity through regulation and programs, adopting models of continuous monitoring of the state of resources to explore.

- Ensure the certification of activities and ventures within the framework of sustainability and community tourism.

- Adoption of guides to good practices and monitoring systems for sustainable tourism development and community tourism.

Current community and sustainable tourism activities require ongoing monitoring and evaluation to guarantee the quality of the services provided and that the load capacity of the territory (LAC) is not exceeded. Several aspects should be considered in this monitoring activity, such as:

- the existence of a national or regional tourism plan

- the model of public participation in the decision process

- the access level and service charge basic infrastructures

- the employed population in the tourism sector

- the school-level of the population

- the percentage of local income generated by tourist activity

- the annual rate of new tourist establishments

- the number of visitors

- the average expenditure per visitor

- the average time for issuing a visa/authorization

One of the models that may ensure that tourism development is contextualized in sustainable development principles and the strategy outlined by the region is through the certification of new establishments, such as resorts, hotels, hostels, and local accommodation, within a system of certification and international recognition as a destination whose potential tourists can consult quickly and effectively. 


\section{Discussion}

The discussion on implementing a proposal for a strategy, and the actions it advocates, for the development of tourism in Oecusse-Ambeno depends on several factors. The factors relate to various cultural and institutional barriers existing in vulnerable countries, and to East Timor in particular. The resolution of such a barrier is preponderant in improving the economic situation of its inhabitants. The need to strengthen community cohesion and organization based on inclusive participation methods (all groups and age groups) will emphasize the need to clarify land tenure and resources as the land is public in East Timor. It will require the conceptual and institutional basis to be modified. On the basis of strengthening the public sector's effectiveness, it will be possible to ensure greater transparency in the transmission of risks and benefits that the different possible options accommodate, and a greater desire to maintain the social traditions and natural heritage of the region.

On the other hand, the marketing promotion of the Oecusse-Ambeno destination must be made in a structured way, where the planning and monitoring of visitor flows, and their impact on local resources (LAC-limit of acceptable change), is monitored and benchmarked based on a set of sustainability indicators. The establishment of partnerships with private institutions and nongovernmental organizations that can bring know-how and investment possibilities to be negotiated and adapted to the region's reality will enable the establishment of a contextualized embracing of the socioeconomic reality and the traditional culture and territory.

The development of the tourism sector can also allow, depending on the public sector's capacity, the reinforcement of investment in accessibilities and infrastructures if adequately designed and managed, and can lead to a transparent and sustained financial management framework.

In today's global market, the tourism business sells integrated products and promotions to potential buyers. The first tourism product is not produced by industry but by the destinations' cultural and natural heritage. In light of sustainable community tourism, it is essential to introduce appropriate marketing tools that promote the destination and its products, and the objectives and practices intended to be implemented in terms of involvement with local communities (Figure 6).



Figure 6. Community traditional practices.

The definition of the touristic product for promotion is linked to the activities and experiences that reflect the target market. Territorial specialization as a tourist offering, 
and the suitability concerning the strategy of the complementarity with the rest of the South-East Asian market, may result in a two-way relationship.

\section{Conclusions}

Sustainable tourism is committed to natural resource conservation and the local community's well-being for its sustainability.

In East Timor, however, tourism has been misused for general development and implemented in the government's environmental policy as wise use of natural resources. The tourism industry cannot settle down properly if the goal is the sector's rapid development or if insufficient consideration is devoted to the principles of sustainable tourism and the actions that need to be implemented. Improving the relationship between the authenticity of the place and the natural context attached to sustainable tourism requires guidelines to orientate visitors and investments.

The existence of a set of planning guidelines applicable to the tourism sector makes it possible for the territorial organization to be defined as a development vector for the region to ensure an increase in infrastructure capacity and, at the same time, promote an increase in the protection and preservation of the environment.

In conclusion, the strategic sustainable planning process is the basis for sustainable decision-making supported on a territorial planning model for a robust and durable tourism sector.

Tourism activity is subject to a context of uncertainty and shocks of changes that often do not originate in the territory in which they operate but are, rather, somewhat beyond their jurisdiction.

The level of uncertainty requires responses to anticipate a wide range of impacts and the necessity of complementary activities to be prepared to strengthen and develop the adaptive capacities of the population and the involved economic actors.

The need to act quickly in changing scenarios leads to the development of resilience in the tourism sector, which will only be possible within a socioenvironmental context in which the destination is betting they will have to respond simultaneously to the more extraordinary social, political, and economic transformations that might occur. The present investigation and thematic line are aimed at strengthening the capacities of population formation. Futures developments have focused on designing a set of guidelines for the construction of public policies that should be monitored for the timely assessment of its ability to reinforce the resilience of the territory and the socioeconomic context of the region.

The limitation of the investigation was based on the lack of data and information, which meant that the entire characterization, assessment, and diagnosis of the reality of the enclave in the Oecusse-Ambeno region was carried out from scratch, but with very considerable support from the ZEESM-Special Administrative Region of OecusseAmbeno of East-Timor.

Author Contributions: Conceptualization, M.A. and E.R.; methodology, M.A.; resources, E.R.; writing—original draft preparation, M.A. and E.R.; writing—review and editing, M.A.; funding acquisition, M.A. All authors have read and agreed to the published version of the manuscript.

Funding: This research was funded by GEOTPU.LAB: grant number FUNDEC/GEOTPU.LAB/ZEESM $n^{\circ}$ 9/2016.

Institutional Review Board Statement: Not applicable.

Informed Consent Statement: Not applicable.

Acknowledgments: The authors acknowledge the ZEESM-Special Administrative Region of Oecusse-Ambeno of East-Timor for the administrative and technical support given.

Conflicts of Interest: The authors declare no conflict of interest. 


\section{References}

1. Jin, X.; Qu, M.; Bao, J. Impact of crisis events on Chinese outbound tourist flow: A framework for post-events growth. Tour. Manag. 2019, 74, 334-344. [CrossRef]

2. Fitzpatrick, D.; Fishman, A. Land Policy and Transitional Justice after Armed Conflicts. In Justice and Economic Violence in Transition. Springer Series in Transitional Justice; Sharp, D., Ed.; Springer: New York, NY, USA, 2014; Volume 5. [CrossRef]

3. Beirman, D. Restoring Tourism Destinations in Crisis: A Strategic Marketing Approach; Routledge: Milton Park, UK, 2020.

4. Hill, H.; Menon, J. ASEAN Economic Integration: Features, Fulfillments, Failures and the Future. 2010. Available online: http:/ /hdl.handle.net/11540/1581 (accessed on 22 April 2021).

5. Honeck, D. LDC Poverty Alleviation and the Doha Development Agenda: Is Tourism Being Neglected? World Trade Organization: Geneva, Switzerland, 2008.

6. Scheyvens, R. Tourism and poverty reduction: Issues for the Small Island States. Tour. Geogr. 2008, 10, 22-41. [CrossRef]

7. Ashley, C.; De Brine, P.; Lehr, A.; Wild, H. The Role of Tourism Sector in Expanding Economic Opportunity, Corporate Social Responsibility Initiative Report 23; Kennedy School of Government, Harvard University: Cambridge, MA, USA, 2007.

8. Krueger, A.O. Trade Policy as an Input to Development. Am. Econ. Rev. 1980, 70, 288-292.

9. Helpman, E.; Krugman, P. Market Structure and Foreign Trade: Increasing Returns, Imperfect Competition, and the International Economy; MIT Press: Cambridge, MA, USA, 1985.

10. WTO-OECD-UNWTO. Aid for Trade and Value Chains in Tourism. 2013. Available online: https://www.wto.org/english/ tratop_e/devel_e/a4t_e/global_review13prog_e/tourism_28june.pdf (accessed on 22 April 2021).

11. Stronza, A.; Gordillo, J. Community views of ecotourism. Ann. Tour. Res. 2008, 35, 448-468. [CrossRef]

12. WTO. The State's Role in Protecting and Promoting Culture as a Factor of Tourism Development and Exploiting the National Cultural Heritage Sites and Monuments for Tourism; WTO: Madrid, Spain, 1985.

13. Toanoglou, M.; Chemli, S.; Valeri, M. The organizational impact of Covid-19 crisis on travel perceived risk across four continents. J. Organ. Chang. Manag. 2021. [CrossRef]

14. Pearce, F. Last Chance to Save the Planet. New Scientist, 30 May 1992; pp. 24-28.

15. Amado, M.P. The operative process in sustainable urban planning. Sustain. Dev. Plan. 2005, 1, $181-191$.

16. Brundtland, G. (Ed.) Report of the World Commission on Environment and Development: Our Common Future; UN General Assembly: New York, NY, USA, 1987.

17. EU. Green Paper on the Urban Environment: Communication from the Commission to the Council and Parliament; European Commission: Brussels, Belgium, 1990.

18. Slocombe, D. Environmental Planning, Ecosystem Science, and Ecosystem Approaches for Environmental Development. Environ. Manag. 1993, 17, 289-303. [CrossRef]

19. Choi, Y.E.; Doh, M.; Park, S.; Chon, J. Transformation Planning of Ecotourism Systems to Invigorate Responsible Tourism. Sustainability 2017, 9, 2248. [CrossRef]

20. Heras, V.C.; Wijffels, A.; Cardoso, F.; Vandesande, A.; Santana, M.; Van Orshoven, J.; Steenberghen, T.; Van Balen, K. A value-based monitoring system to support heritage conservation planning. J. Cult. Herit. Manag. Sustain. Dev. 2013, 3, 130-147. [CrossRef]

21. Angelevska-Najdeska, K.; Rakicevik, G. Planning of Sustainable Tourism Development. Procedia Soc. Behav. Sci. 2012, 44, 210-220. [CrossRef]

22. Zhao, W.; Brent Ritchie, J.R. Tourism and poverty alleviation: An integrative research framework in the viability of the destination. Curr. Issues Tour. 2007, 10, 119-143. [CrossRef]

23. Asif Khan, A.; Bibi, S.; Lorenzo, A.; Lyu, J.; Babar, Z.U. Tourism and Development in Developing Economies: A Policy Implication Perspective. Sustainability 2020, 12, 1618. [CrossRef]

24. Zemła, M. Reasons and Consequences of Overtourism in Contemporary Cities-Knowledge Gaps and Future Research. Sustainability 2020, 12, 1729. [CrossRef]

25. GEOTPU.LAB. Plano Director de Ordenamento Territorial da Região Administrativa Especial de Oé-Cusse Ambeno, East-Timor. Available online: https:/ / 88915ef1-48c9-4622-b824-80b0eaee1eff.filesusr.com/ugd/95f651_35556af2335d4847ba69b531d831f3 27.pdf (accessed on 22 April 2021). (In Portuguese).

26. Zhuang, X.; Yao, Y.; Li, J. Sociocultural Impacts of Tourism on Residents of World Cultural Heritage Sites in China. Sustainability 2019, 11, 840. [CrossRef]

27. Manson, P. Tourism Impacts, Planning and Management; Butterworth-Heinemann: Oxford, UK, 2003; ISBN 075065970X.

28. Yanes, A.; Zielinski, S.; Cano, M.D.; Seong-il, K. Community-Based Tourism in Developing Countries: A Framework for Policy Evaluation. Sustainability 2019, 11, 2506. [CrossRef]

29. Hall, D.; Gössling, C.M.; Scott, S. (Eds.) The Routledge Handbook of Tourism and Sustainability; Routledge: New York, NY, USA, 2015.

30. Hall, C.M. A typology of governance and its implications for tourism policy analysis. J. Sustain. Tour. 2011, 19, 37-41. [CrossRef]

31. Weidenfeld, A. Tourism Diversification and Its Implications for Smart Specialisation. Sustainability 2018, 10, 319. [CrossRef]

32. UNEP-United Nations Environment Programme; WTO-World Tourism Organization. Making Tourism More Sustainable; UNEP/WTO: Paris, France, 2005; ISBN 9280725076.

33. Schellhorn, M. Development for whom? Social justice and the business of ecotourism. J. Sustain. Tour. 2010, 18, 115-135. [CrossRef] 
34. Almeida-García, F. Analysis of tourism policy in a developing country: The case of Morocco. J. Policy Res. Tour. Leis. Events 2018, 10, 48-68. [CrossRef]

35. Ralf Buckley, R. Tourism in the Most Fragile Environments. Tour. Recreat. Res. 2000, 25, 31-40. [CrossRef]

36. Arkema, K.K.; Fisher, D.M.; Wyatt, K.; Wood, S.A.; Payne, H.J. Advancing Sustainable Development and Protected Area Management with Social Media-Based Tourism Data. Sustainability 2021, 13, 2427. [CrossRef]

37. Batista e Silva, F.; Herrera, M.A.M.; Rosina, K.; Barranco, R.R.; Freire, S.; Schiavina, M. Analysing spatiotemporal patterns of tourism in Europe at high-resolution with conventional and big data sources. Tour. Manag. 2018, 68, 101-115. [CrossRef]

38. Chemli, S.; Toanoglou, M.; Valeri, M. The impact of Covid-19 media coverage on tourist's awareness for future travelling. Curr. Issues Tour. 2020, 1-8. [CrossRef]

39. Dandekar, H.C. Qualitative methods in planning research and practice. J. Archit. Plan. Res. 2005, 22, $129-137$.

40. Ahmad, A.; Jamaludin, A.; Zurami, N.S.M.; Valeri, M. Visit Intention and Destination Image in Post- Covid- 19 Crisis Recovery. Curr. Issues Tour. 2020, 24, 2392-2397. [CrossRef]

41. GEOTPU.LAB. Programa Estratégico de Desenvolvimento Turístico da Região Administrativa Especial de Oé-Cusse Ambeno, East-Timor; GEOTPU.LAB: Lisboa, Portugal, 2016. (In Portuguese)

42. ILO-International Labour Organization. The ILO in Indonesia; ILO Country Office for Indonesia and Timor-Leste. Available online: https://www.ilo.org/wcmsp5/groups/public/---asia/---ro-bangkok/---ilo-jakarta/documents/publication/wcms_ 675335.pdf (accessed on 22 April 2021).

43. Gross, M.; Brown, G. An empirical structural model of tourists and places: Progressing involvement and place attachment into tourism. Tour. Manag. 2008, 29, 1141-1151. [CrossRef]

44. Hall, C.M.; Malinen, S.; Vosslamber, R.; Wordsworth, R. (Eds.) Business and Post-Disaster Management: Business, Organisational and Consumer Resilience and the Christchurch Earthquake; Routledge: Milton Park, UK, 2016.

45. Houk, R.J. Drama of Portuguese Timor-Portugues. Ann. Am. Acad. Political Soc. Sci. 1978, 436, 163-164.

46. Direcção Nacional de Estatística de Timor-Leste. Population Counts from 2004 Census. Dili: Ministry of Planning and Finance. 2005. Available online: http:/ / dne.mopf.gov.tp/census/ (accessed on 22 April 2021).

47. Li, Q.; Wen, M. The Immediate and Lingering Effects of Armed Conflict on Adult Mortality: A Time-Series Cross-National Analysis. J. Peace Res. 2005, 42, 471-492. [CrossRef]

48. Ghobarah, H.A.; Huth, P.; Russet, B. Comparative Public Health: The Political Economy of Human Misery and Well-Being. Int. Stud. Q. 2004, 48, 73-94. Available online: www.jstor.org/stable/3693564 (accessed on 15 August 2021). [CrossRef]

49. Kiernan, B. Cover-up and denial of genocide-Australia, The USA, East Timor, and the Aborigines. Crit. Asian Stud. 2002, 34, 163-192. [CrossRef]

50. Chomsky, N. Why Americans Should Care about East Timor. Mother Jones 1999. Available online: http://www.motherjones. com/east_timor/ (accessed on 22 April 2021).

51. Hull, T. From province to nation: The demographic revolution of a people. In Out of the Ashes: Destruction and Reconstruction of East Timor; Fox, J.J., Soares, D.B., Eds.; Australian National University Press: Canberra, Australia, 2003.

52. Shondell Miller, D. Disaster tourism and disaster landscape attractions after Hurricane Katrina. Int. J. Cult. Tour. Hosp. Res. 2008, 2, 115-131. [CrossRef]

53. Ritchie, B.W. Crisis and Disaster Management for Tourism; Channel View Publications: Bristol, UK, 2009.

54. Ritchie, B.W.; Campiranon, K. (Eds.) Tourism Crisis and Disaster Management in the Asia-Pacific; CABI: Wallingford, UK, 2015.

55. Pforr, C.; Hoise, P. (Eds.) Crisis Management in the Tourism Industry; Ashgate Publishing: Farnham, UK, 2009.

56. Cheer, J.M.; Lew, A.A. (Eds.) Tourism, Resilience and Sustainability: Adapting to Social, Political and Economic Change; Routledge: Milton Park, UK, 2017.

57. IUCN. 21st Conference of the Parties (COP21) to the United Nations Framework Convention on Climate Change (UNFCCC); IUCN: Paris, France, 2015.

58. Hewlett, D.; Edwards, J. Beyond prescription: Community engagement in the planning and management of national parks as tourist destinations. Tour. Plan. Dev. 2013, 10, 45-63. [CrossRef] 